\title{
Análisis de los contenidos de Química impartidos en Escuelas Secundarias Estaduales de la Municipalidad de Confresa/MT
}

Lunara Lanna Lima

lunaralanna@gmail.com

https://orcid.org/0000-0002-4396-1800

Marcelo Franco Leão

marcelo.leao@cfs.ifmt.edu.br

http://orcid.org/0000-0002-9184-916X

Instituto Federal de Mato Grosso (IFMT) Campus Confresa

Brasil

Recibido: 2020-07-17; Aceptado: 2020-11-30

\section{Resumen}

Es necesario reflexionar sobre el currículo escolar, ya que permite comprender los aspectos estructurales de la enseñanza de la química. El presente estudio tuvo como objetivo analizar los contenidos impartidos en la disciplina de química en la escuela secundaria en un municipio de Mato Grosso y así verificar si cumplían con la legislación vigente y las especificidades locales. Fue una investigación documental, con un enfoque cualitativo, relacionada con los diarios de clase de esta disciplina en el año 2017, que se solicitó a los coordinadores pedagógicos y secretarios de las 8 con Escuela Secundaria estatales en Confresa/MT. El análisis de los documentos consideró las siguientes categorías: contextualización, interdisciplinariedad, historia de la ciencia y contenido con características innovadoras. Por lo tanto, se verificó en qué unidades escolares se cumplieron completamente las Directrices Curriculares de Mato Grosso, en las que hubo adiciones de contenido y si eran relevantes para la comunidad local. Aunque es el mismo contexto, se observó que el plan de estudios mostraba diferencias, con especificidades socioculturales, es decir, eran diferentes entre las unidades, incluso en cantidad y profundidad. Se cree que las concepciones pedagógicas de los docentes llevaron a la elaboración de diferentes planes, con enfoques más tradicionales y otros más innovadores.

Palabras clave: Plan de estudios de química, Escuela Secundaria, pautas curriculares.

\section{Analysis of the contents of Chemistry taught in High School of State Schools in the Municipality of Confresa/MT}

\begin{abstract}
Reflection on the school curriculum is necessary, as it allows understanding structural aspects of chemistry teaching. The present study aimed to analyze the contents taught in the discipline of chemistry in high school in a municipality in Mato Grosso and thus verify whether they met the current legislation and local specificities. It was a documentary research, with a qualitative approach, related to the class diaries of this discipline in the year 2017, which were requested to the pedagogical coordinators and secretaries of all 8 state schools with High School in Confresa/MT. The analysis of the documents considered the following categories: contextualization, interdisciplinarity, history of science and content with innovative
\end{abstract}


characteristics. Thus, it was verified in which school units the Mato Grosso Curricular Guidelines were fully met, in which there was an increase in content and if they were relevant to the local community. Although it is the same context, it was noticed that the curriculum showed differences, with socio-cultural specificities, that is, they were different between the units, including in quantity and depth. It is believed that the pedagogical conceptions of teachers led to the elaboration of different plans, with more traditional and other more innovative approaches.

Keywords: Chemistry Curriculum, High School, Curricular Guidelines.

\section{Análise dos conteúdos de Química ministrados no Ensino Médio das Escolas Estaduais do Município de Confresa/MT}

\section{Resumo}

A reflexão sobre o currículo escolar é necessária, pois permite compreender aspectos estruturais do ensino de química. O presente estudo teve como objetivo analisar os conteúdos ministrados na disciplina de química no Ensino Médio de um município mato-grossense e assim verificar se atenderam a legislação vigente e as especificidades locais. Tratou-se de uma pesquisa documental, com abordagem qualitativa, relativa aos diários de classe desta disciplina do ano de 2017, que foram solicitados aos coordenadores pedagógicos e secretários de todas as 8 escolas estaduais com Ensino Médio de Confresa/MT. A análise dos documentos considerou as seguintes categorias: contextualização, interdisciplinaridade, história da ciência e conteúdos com características inovadoras. Assim, foi verificado em quais unidades escolares as Orientações Curriculares de Mato Grosso foram plenamente atendidas, em quais houve acréscimos de conteúdos e se eles tinham relevância para a comunidade local. Embora seja um mesmo contexto, percebeu-se que o currículo apresentou diferenças, com especificidades socioculturais, ou seja, foram diferentes entre as unidades, inclusive na quantidade e profundidade. Acredita-se que as concepções pedagógicas dos professores levaram a elaboração de planejamentos diferentes, com abordagens mais tradicionais e outras mais inovadoras.

Palavras-chave: Currículo de química, Ensino Médio, Orientações Curriculares.

\section{Introdução}

$\mathrm{Na}$ atualidade, muito se tem discutido sobre currículo educacional no Brasil, e a partir dessas discussões, surgiram duas correntes de pensamento: uma que defende um currículo básico único e a outra vertente que defende a autonomia das escolas para determinar o currículo escolar e assim atender as especificidades locais.

No intuito de dirimir divergências, o Ministério da Educação (MEC) elaborou uma Base Nacional Comum Curricular (BNCC), que contém um currículo mínimo obrigatório, ou seja, não aponta diretamente os conteúdos básicos, mas sim as competências e habilidades que todo estudante deveria aprender/desenvolver durante aquela determinada etapa da escolarização. Não se entrará em detalhes sobre a BNCC, uma vez que ela não estava vigente no ano investigado. 
De acordo com o MEC, a BNCC vem com o intuito de diminuir as desigualdades sociais. No entanto, para não desconsiderar as especificidades regionais e particularidades de cada unidade escolar, permaneceu certa autonomia ao professor para acrescentar conteúdos relacionados a sua realidade e suas próprias metodologias.

Baseando-se nessa autonomia que o professor tem para elaborar o currículo escolar, pressupõe-se que resulte em diferenças significativas, tanto nos conteúdos ministrados na disciplina de química das diferentes escolas, quanto na profundidade como que eles são abordados, mesmo sendo escolas da mesma rede (Estadual) e instaladas no mesmo município (Confresa/MT). Assim, esta pesquisa buscou analisar os conteúdos ministrados na disciplina de química no Ensino Médio desse município mato-grossense, e assim verificar tendências no ensino, além de constatar se atenderam a legislação vigente e as especificidades locais.

A problemática discutida envolveu a quantidade de conteúdos trabalhados, as diferenças na abordagem dos mesmos e até que ponto as escolas levaram em consideração o que está preconizado pelas Orientações Curriculares do Estado de Mato Grosso (OC). É preciso considerar que os estudantes de uma determinada escola podem ter estudado, durante o ano, quantidades de conteúdos maiores, que posteriormente foram cobrados nos seletivos para a Educação Superior, com metodologias didático-pedagógicas que promoveram aprendizagens diferentes e, uma vez estudando dessa maneira, tiveram hipoteticamente maiores vantagens, mesmo tendo estudado na mesma rede de ensino. Ou ainda o fato de precisar de mobilidade dentro do mesmo município já sentiram consideráveis diferenças.

Por essas questões, buscou-se inicialmente descrever os conteúdos trabalhados, no entanto, ao analisar os diários, encontrou-se também registros de abordagens metodológicas e por meio destes, analisou-se as estratégias de ensino. Nessa pesquisa analisou-se os conteúdos ministrados em turmas do Ensino Médio de escolas diferentes, se a grade curricular estabelecida pelas OC e Parâmetros Curriculares Nacionais (PCN) foi trabalhada por completo em todas as unidades, se houve conteúdos acrescentados e se estes tiveram relevância para a comunidade.

\section{Fundamentos teóricos sobre o currículo escolar de química}

O currículo escolar pode ser descrito como a totalidade das ações (essenciais, dentro das suas especificidades), desenvolvidas no núcleo escolar (Saviani, 2011). Este tema, há décadas tem gerado calorosas discussões e a proposta de um currículo nacional comum impulsionou 
grandemente esse debate. A perspectiva do MEC era proporcionar isonomia em relação aos conteúdos aprendidos entre todos os estudantes brasileiros. A proposta da BNCC partiu da ideia de direito a aprendizagem de conteúdos básicos, mas permanecendo certa autonomia a escola para diversificar o restante do currículo, garantindo multiplicidade conforme as concepções pedagógicas, especificidades e preferências dos jovens (Moehlecke, 2012).

Os temas tratados nas escolas são os norteadores dos conhecimentos e valores que a sociedade adquirirá. Baseando-se nessa premissa, Prado (2000), reafirma que a importância de um currículo comum parte do percurso educativo de suas crianças e jovens. O currículo traz a elaboração dos conteúdos, metodologias e formas de avaliação de acordo com os objetivos que se deseja atingir. Esses conhecimentos e valores são modificados conforme às transformações. A autora alicerça a ideia de um currículo comum justamente na diversidade brasileira, que segundo ela, provoca discrepâncias quanto ao acesso aos centros de produção de conhecimento, o que não favorece a existência de uma equidade na qualidade da oferta de ensino das escolas públicas brasileiras.

Todavia, o conhecimento escolar também precisa ser mediado pela cultura, pois há conhecimentos culturais que precisam ser passados de geração para geração. Para que tais conhecimentos se tornem constituintes do conhecimento escolar é necessário que estes sejam incluídos no currículo e que não se priorize a excessiva quantidade de conceitos, mas sim a qualidade, pelo qual a química seja ensinada como um conhecimento ligado a suas origens científicas, ao contexto sociocultural e também tecnológico (Mortimer, 2000).

De acordo com as OC de MT:

No Ensino Médio, o que se pretende é que o estudante compreenda os processos químicos relacionados às suas aplicações tecnológicas, ambientais e sociais, de modo que possa emitir juízos de valor e tomar decisões de maneira crítica, responsável e com seriedade, tanto individual quanto coletivamente. Para que isso ocorra, a aprendizagem de conteúdos é fundamental, mas deve estar associada às capacidades relacionadas a saber fazer, saber conhecer, saber ser e saber ser em sociedade (Mato Grosso, 2010, p. 90).

É importante que o estudante desenvolva um senso crítico e responsável para tomar decisões, aprenda os conteúdos, mas que compreenda a relação e implicações que eles têm com a sua realidade. 
Uma das vantagens da BNCC seria que ela indica indiretamente os conteúdos dos exames, o que teoricamente garante maior paridade aos estudantes. Contudo, segundo Silva (2015, p. 375): "Isso nos leva a uma lógica paradoxal a partir da qual nos vemos como que andando em círculo: dos exames para o currículo e do currículo para os exames."

Em seus estudos, Lopes (2002) considera necessário questionar os objetivos e consequências para nossa sociedade de um currículo nacional comum:

Não apenas pelo fato de ser uma proposta curricular que se insere nas políticas de conhecimento oficial, que visam à homogeneidade cultural e o controle acentuado da educação, com base em princípios de mercado, estabelecidas na atualidade em países que assumem políticas neoliberais. Mas também porque, em seus princípios de organização curricular tão divulgados como representação do novo e do revolucionário no ensino, permanece uma orientação que desconsidera o entendimento do currículo como política cultural e ainda reduz seus princípios à inserção social e ao atendimento às demandas do mercado de trabalho (Lopes, 2002, p. 396).

Como é possível perceber, há uma dualidade que envolve os objetivos da formação da educação básica. De acordo com Moehlecke (2012), um currículo nacional comum tem como objetivo, prioritariamente, formar para o trabalho, o que pode indiretamente diminuir o poder de escolha, o que ocasionaria carreiras preestabelecidas com pouca diversidade. Partindo dessa hipótese, a autora defende um currículo diversificado e múltiplo.

Fazenda (1998), evoca a questão da fragmentação das disciplinas como um problema para a aprendizagem, fato facilmente percebido na área de ciências da natureza. A autora evidencia a necessidade de um ensino de conceitos entrelaçados, as disciplinas não devem possuir delimitação de fronteiras, para que se desenvolva o projeto educacional como um todo.

As OC, os PCN e até mesmo a BNCC, trazem a química como uma ciência muito presente no cotidiano, que necessita ser ensinada quase que, como algo corriqueiro. Os PCN consideram que a química “está presente e deve ser reconhecida nos alimentos e medicamentos, nas fibras têxteis e nos corantes, nos materiais de construção e nos papéis, nos combustíveis e nos lubrificantes, nas embalagens e nos recipientes" (Brasil, 1999, p. 10).

Os PCN+, publicado em 2002, também considera que:

A Química pode ser um instrumento da formação humana, que amplia os horizontes culturais e a autonomia, no exercício da cidadania, se o conhecimento químico for promovido como um dos meios de interpretar o mundo e intervir na realidade, e, se for apresentado como ciência, com 
seus conceitos, métodos e linguagens próprios, e como construção histórica, relacionada ao desenvolvimento tecnológico e aos muitos aspectos da vida em sociedade (Brasil, 2002, p. 87).

$\mathrm{O}$ ensino descontextualizado da química, se torna inútil, restringindo-se meramente a finalidade de passar em exames vestibulares, sem se preocupar com a geração de indivíduos acríticos que pouco sabem de fato sobre ciências e construção do conhecimento (Chassot, 2000). O ensino da química deve se preocupar em preparar o cidadão para a vida cotidiana (Chassot, 1990).

No entanto, a listagem de conteúdos do Exame Nacional do Ensino Médio (ENEM), sugere indiretamente, um ensino mais tradicional, pois para que todos os conteúdos da lista sejam trabalhados, os professores podem sucumbir a metodologias sistemáticas baseadas em memorização de conceitos, sem interligação com fenômenos e contextualizações cotidianas, regredindo em relação aos avanços para uma educação mais inovadora, como sugere Maceno $e t$ al. (2011).

A forma como a avaliação se dá é bastante contraditória, hora os documentos oficiais pregam um ensino crítico e contextualizado, remetendo-se a tendências pedagógicas inovadoras, na outra, pratica métodos de avaliação para ingresso na Educação Superior conteudistas apontando para tendências pedagógicas tradicionais.

A própria OC de MT diz que:

Não é preciso fazer uma análise aprofundada nos nossos currículos atuais para verificar o número excessivo de conceitos, cuja inter-relação dificilmente será percebida pelos estudantes. A quantidade de conceitos/definições e procedimentos que são introduzidos a cada aula é muito grande para que seja possível ao estudante, em tão pouco tempo, compreendê-los e ligá-los logicamente numa estrutura mais ampla que dê significado à aprendizagem (Mato Grosso, 2010, p. 92).

É importante destacar que as OC de MT não determinaram uma cronologia dos conteúdos para as séries/anos do Ensino Médio. Estes foram balizados em torno das propriedades, constituição e transformações da matéria e também, segundo essas orientações “Os conceitos podem ser abordados em diferentes momentos e níveis de profundidade.” (Mato Grosso, 2010, p. 93).

“A Química é uma ciência experimental e como tal deverá apresentar-se em sala de aula, sempre que possível, com atividades práticas" (Mato Grosso, 2010, p. 98). Pois tem sido considerada uma das disciplinas mais difíceis de se aprender. Tendo em vista a busca por 
soluções, as aulas práticas vêm sendo consideradas como uma ferramenta para construir uma aprendizagem mais significativa e desenvolver maior simpatia, por parte dos estudantes, à disciplina de química (Casteleins, 2011).

Herber, (2007), e Damasceno, Wartha e Silva, (2009), são alguns dos pesquisadores que tem buscado entender a aplicação e implicações do currículo básico, na prática, trazendo em seus relatos como de fato tem se dado e suas perspectivas quanto ao assunto.

Outro detalhe observado é que as políticas de currículo nacional comum para o Ensino Médio, que deveriam ser executadas em todas as escolas de ensino básico brasileiro. Na prática, não são efetivamente incorporadas pelas unidades de ensino estaduais e municipais, o que demonstra certa distância entre a proposta e os atores responsáveis pela execução dessas políticas curriculares (Martins, 2000). Surgiu então a proposta de verificar como foi desenvolvido o currículo de química nas escolas Estaduais de Confresa/MT, no ano de 2017.

\section{Procedimentos Metodológicos}

Este estudo configurou-se como uma pesquisa documental qualitativa, de natureza básica, onde analisou-se os conteúdos ministrados na disciplina de química no Ensino Médio de um município mato-grossense e comparou-se com o documento vigente, intitulado "Orientações Curriculares: Área de Ciências da Natureza e Matemática” (Mato Grosso, 2010). A pesquisa documental se baseia na coleta de informação via documentos, que podem ser escritos, visuais e também auditivos (Fachin, 2006).

A pesquisa iniciou-se com a definição do objeto de estudo, seguida da coleta dos documentos para análise dos dados. Seu desenvolvimento aconteceu entre setembro de 2018 e junho de 2020, sendo escolhido como objeto de estudo o currículo de química registrado nos diários de classe das turmas de escolas estaduais do município de Confresa/MT, no ano de 2017. Cabe ressaltar que este município fica localizado na região nordeste do Estado e distante entorno de $1.200 \mathrm{Km}$ da capital Cuiabá/MT.

Os diários da disciplina de química, referente aos conteúdos, ministrados no Ensino Médio, no ano de 2017, exclusivamente das escolas estaduais deste município, foram solicitados à assessoria da SEDUC em Confresa/MT, que indicou contato direto com as escolas, informando e-mail e telefone. Via endereço eletrônico apenas uma escola respondeu. Assim, foi necessário entrar em contato com os secretários e coordenadores pedagógicos das respectivas 
escolas, e técnicos da Assessoria Pedagógica, de maneira presencial ou ainda via redes sociais, isso repetidas vezes, até que, a obtenção dos documentos deu-se por completo, totalizando 53 diários de turmas de química ofertadas naquele ano letivo.

As escolas analisadas foram citadas nos resultados por meio de códigos de identificação, constituídos por letras e números, ou seja, cada escola do município foi representada por uma letra, que vai do $\mathrm{A}$ ao $\mathrm{H}$, e como algumas escolas possuíam mais de uma modalidade de ensino ou extensões (unidades que funcionavam de forma anexa a elas), estas modalidades (diferentes da regular), como educação de jovens e adultos (EJA), Ensino Médio Integrado a Educação Profissional (EMIEP) e extensões foram codificadas com números após a letra da respectiva escola.

Segue abaixo, no quadro 1, o nome das escolas, os anos do Ensino Médio ofertados por escola e suas extensões no ano de 2017, sua especificidade (urbana, campo ou indígena) e seus códigos a serem utilizados nos resultados.

Quadro 1: Nomes das escolas, os anos do Ensino Médio ofertadas por elas, suas especificidades e seus códigos a serem usados nos resultados.

\begin{tabular}{|c|c|c|}
\hline Nome das escolas e suas extensões & $\begin{array}{l}\text { Anos do Ensino } \\
\text { Médio ofertados }\end{array}$ & $\begin{array}{l}\text { Código de } \\
\text { identificação }\end{array}$ \\
\hline Antônio Alves Dias (campo) - Regular & $1^{\mathrm{a}}, 2^{\mathrm{a}}$ e $3^{\mathrm{a}}$ & $\mathbf{A}$ \\
\hline Antônio Alves Dias - EJA. & $1^{\mathrm{a}} \mathrm{e} 2^{\mathrm{a}}$ & A1 \\
\hline Extensão Tancredo Neves - Regular. & $1^{a}, 2^{a}$ e $3^{a}$ & $\mathrm{~A} 2$ \\
\hline Extensão Tancredo Neves - EJA. & $1^{a}$ e $2^{a}$ & A3 \\
\hline Extensão Pau Brasil - Regular. & $1^{\mathrm{a}}, 2^{\mathrm{a}}$ e $3^{\mathrm{a}}$ & A4 \\
\hline Extensão Pau Brasil - EJA. & $1^{\mathrm{a}} \mathrm{e} 2^{\mathrm{a}}$ & A5 \\
\hline CEJA Creuslhi de Souza Ramos (urbana). & Única. & B \\
\hline Santo Antônio (campo)- Regular. & $1^{\mathrm{a}}, 2^{\mathrm{a}}$ e $3^{\mathrm{a}}$ & $\mathbf{C}$ \\
\hline Santo Antônio - EJA. & $1^{\mathrm{a}} \mathrm{e} 2^{\mathrm{a}}$ & $\mathrm{C} 1$ \\
\hline Sol Nascente (campo)- Regular. & $1^{\mathrm{a}}, 2^{\mathrm{a}}$ e $3^{\mathrm{a}}$ & D \\
\hline Sol Nascente -EJA. & $1^{a}, 2^{a}$ e $3^{a}$ & D1 \\
\hline Sol Nascente - Indígena. & $1^{\mathrm{a}}$. & D2 \\
\hline Tiradentes CB José Martins de Moura (urbana). & $1^{\mathrm{a}}, 2^{\mathrm{a}}$ & $\mathbf{E}$ \\
\hline 29 de Julho - Regular(urbana). & $1^{\mathrm{a}}, 2^{\mathrm{a}}$ e $3^{\mathrm{a}}$ & $\mathbf{F}$ \\
\hline
\end{tabular}




\begin{tabular}{|c|c|c|}
\hline 29 de Julho - EMIEP. & $1^{\mathrm{a}}, 2^{\mathrm{a}}$ e $3^{\mathrm{a}}$ & F1 \\
\hline Waldir Bento da Costa (campo) -regular. & $1^{\mathrm{a}}, 2^{\mathrm{a}}$ e $3^{\mathrm{a}}$ & $\mathbf{G}$ \\
\hline Waldir Bento da Costa - EJA. & $1^{\mathrm{a}} \mathrm{e} 2^{\mathrm{a}}$ & G1 \\
\hline Waldir Bento da Costa -Extensão Branca de Neve - Regular. & $1^{\mathrm{a}}, 2^{\mathrm{a}}$ e $3^{\mathrm{a}}$ & G2 \\
\hline Waldir Bento da Costa -Extensão Branca de Neve -EJA. & $1^{\mathrm{a}}$ e $2^{\mathrm{a}}$ & G3 \\
\hline Waldir Bento da Costa - Extensão Bridão - Regular. & $1^{\mathrm{a}}, 2^{\mathrm{a}}$ e $3^{\mathrm{a}}$ & G4 \\
\hline Waldir Bento da Costa -Extensão Bridão - EJA. & $1^{\mathrm{a}} \mathrm{e} 2^{\mathrm{a}}$ & G5 \\
\hline Indígena Tapi Itãwa (indígena). & $1^{\mathrm{a}}$ e $2^{\mathrm{a}}$ & $\mathbf{H}$ \\
\hline
\end{tabular}

Fonte: Dados coletados na pesquisa (2018-2020).

Para sinalizar comentários pontuais, será utilizado asterisco $(*)$ a frente da letra $\left(\mathrm{A}^{*}\right)$ que serão explanadas logo abaixo dos quadros. E para sinalizar que determinado conteúdo foi trabalhado de forma bastante detalhada por determinada unidade, será usado dois asteriscos (**) a frente da letra símbolo da turma $\left(\mathrm{A}^{* *}\right)$.

A escola A teve, no ano de 2017, as aulas de algumas de suas unidades (não especificouse quais unidades devido ao fato de nem todos os documentos desta escola terem sido enviados com datas, mas percebeu-se essa diferença de início das aulas entre diários que foram entregues datados) iniciadas no final de abril, segundo a coordenação atual, este fato se deu provavelmente devido à greve da rede municipal de ensino e a necessidade da escola $\mathrm{A}$ de acompanhar o calendário dela, por questões de infraestrutura.

Não houve turma formada de terceiro ano, devido a demanda insuficiente de estudantes, nem a modalidade EJA na escola H em 2017 por falta de salas de aulas. Essas informações foram passadas pelo secretário da escola via rede social. A unidade E teve em 2017 o seu primeiro ano de funcionamento, portanto não ofertou terceiro ano por baixa demanda, de acordo com a secretária.

A unidade D2 iniciou o ano letivo em setembro de 2017, devido a questões documentais e ofertou apenas primeiro ano, provavelmente por questões de demanda, de acordo com o secretário (este não trabalhava nesta unidade em 2017), sendo assim verificou-se apenas registros do terceiro e quarto bimestre.

A escola B funcionava na modalidade carga horária etapa, na qual os estudantes tinham que perfazer 100 horas para finalizar a disciplina de química do Ensino Médio. Devido a esse fato, o diário da escola B foi lançado por estudante, referente ao dia que ele frequentou e não por turma. Para categorizar os conteúdos da unidade B, se fez necessário analisar todos os 
diários de todos os estudantes de uma determinada turma, analisando e anotando as datas de forma a organizar a ordem cronológica anual com todas as datas que foram ministradas aulas de química no ano de 2017, utilizando estudantes diferentes, mas da mesma turma (pois o conteúdo em cada data foi o mesmo), pois como era por carga horária, era comum um estudante terminar o ano em abril, por exemplo, ou iniciar em outubro. Por ser por carga horária, os conteúdos da unidade B aparecerão nos quadros de conteúdos dos três anos do Ensino Médio.

A metodologia de análise aproxima-se na Análise de conteúdo de Bardin (2011), na qual baseou-se em categorização semântica preestabelecida, seguida da coleta e exploração dos documentos para inferência e interpretação dos dados (Bardin, 2011). Os temas foram: contextualização, interdisciplinaridade, história da ciência e conteúdos com características inovadoras. Na categoria sobre história da ciência, considerou-se quando mencionaram nos registros a palavra história, quando ficou subentendido se tratar de um acontecimento histórico e menções a nome do de cientistas.

Após os dados serem submetidos a análise interpretativa, estes foram descritos concisamente na forma de quadros. Fez-se as devidas discussões e na sequência, foram elaboradas as conclusões de forma resumida, com o propósito de evidenciar as observações mais importantes, contendo as recomendações de acordo com os resultados.

\section{Resultados e Discussões}

A primeira categoria analisada foram os conteúdos, ou seja, os principais conceitos químicos que constituem o currículo seguir são detalhados, nos quadros 2, 3 e 4, todos os temas de química trabalhados nos primeiros, segundos e terceiros anos do Ensino Médio das escolas estaduais do município de Confresa/MT, por ordem decrescente de conteúdos mais ministrados.

Cabe ressaltar que a unidade B aparece no quadro 2, 3 e 4, porque sua modalidade é única e por quantidade de horas, em teoria, abrange todos os anos do Ensino Médio. No entanto percebeu-se que, a maioria são conteúdos ministrados, geralmente no primeiro ano do Ensino Médio, mas que aparecem nos quadros de outros anos porque muitas escolas variaram o ano em que ministraram alguns conteúdos, o que resultou em conteúdos como ligações químicas e funções inorgânicas, presentes nos quadros de conteúdos dos primeiros, segundos e terceiros anos. 
A unidade D2 iniciou as atividades em setembro, pois, pelo que foi informado pelo secretário, que não trabalhava na unidade sede na época, os documentos que permitiam a abertura desta extensão foram publicados nesse período do ano, os estudantes estavam estudando em outra unidade antes disso. Está unidade registrou duas temáticas apenas, sendo uma delas da área específica de biologia, no entanto apresentou o conteúdo bastante contextualizado.

Embora se trate do mesmo município e o meio sociocultural seja bastante semelhante para a maioria das escolas, os conteúdos ministrados, como já se esperava, apresentaram diferenças significativas. Isso provavelmente é resultado das diferentes concepções pedagógicas dos professores que resultam na elaboração de planejamentos diferentes com tempos de execuções diferentes, resultando em quantidades maiores ou menores de conteúdos ministrados (também depende de outros fatores como a carga horária das aulas), com abordagens tradicionais ou inovadoras e também as especificidades de cada localidade.

Quadro 2: Conteúdos de química trabalhados nas turmas de primeiro ano

\begin{tabular}{|c|c|c|c|c|c|}
\hline Substâncias & $\begin{array}{l}\text { Ligações } \\
\text { químicas }\end{array}$ & $\begin{array}{l}\text { Propriedades } \\
\text { da matéria }\end{array}$ & $\begin{array}{c}\text { Transformações/reações } \\
\text { químicas }\end{array}$ & $\begin{array}{c}\text { Misturas, fases } \\
\text { e separação }\end{array}$ & $\begin{array}{r}\text { Estados } \\
\text { físicos da matéria }\end{array}$ \\
\hline $\begin{array}{l}\mathrm{A} 1, \mathrm{~A} 2, \mathrm{~A} 3, \\
\mathrm{~A} 4, \mathrm{~A} 5, \mathrm{~B}, \mathrm{C}, \\
\mathrm{C} 1, \mathrm{D}, \mathrm{D} 1, \mathrm{E}, \\
\mathrm{F}, \mathrm{F} 1, \mathrm{G}, \mathrm{G} 1, \\
\text { G3 e G4. }\end{array}$ & $\begin{array}{l}\text { A, A2, B, C1, } \\
\text { D1**, E, F, F1, } \\
\text { G, G1, G2, G3 } \\
\text { e G4. }\end{array}$ & $\begin{array}{l}\mathrm{A}, \mathrm{A} 2, \mathrm{~A} 3, \\
\mathrm{~A} 5, \mathrm{C}, \mathrm{D}, \mathrm{D} 1, \\
\mathrm{E}, \\
\mathrm{F}^{* *}, \mathrm{~F} 1 * * \\
\mathrm{G} 1, \mathrm{G} 2 \text { e G4. }\end{array}$ & $\begin{array}{c}\text { A3, A5, C, C1, D, D1, } \\
\text { D2, F, F1, G2, G4, G5 e } \\
\mathrm{H}^{* *} .\end{array}$ & $\begin{array}{l}\text { A, A2, A3, A4, } \\
\text { A5, B, C, C1, } \\
\text { D, D1, E e G4. }\end{array}$ & $\begin{array}{l}\mathrm{A}, \mathrm{A} 1, \mathrm{~A} 2, \\
\mathrm{~A} 3, \\
\mathrm{~A} 4, \mathrm{~A} 5, \mathrm{~B}, \\
\mathrm{G}, \mathrm{G} 2, \mathrm{G} 1, \mathrm{G} 4 \mathrm{e} \\
\mathrm{H}^{* *} .\end{array}$ \\
\hline $\begin{array}{l}\text { Química, } \\
\text { tecnologia e } \\
\text { sociedade }\end{array}$ & $\begin{array}{l}\text { Unidades de } \\
\text { medida e } \\
\text { grandezas }\end{array}$ & $\begin{array}{l}\text { Átomo - } \\
\text { partículas }\end{array}$ & $\begin{array}{l}\text { Tabela Periódica e os } \\
\text { elementos químicos }\end{array}$ & $\begin{array}{l}\text { Modelos } \\
\text { atômicos }\end{array}$ & $\begin{array}{l}\text { Matéria e } \\
\text { energia }\end{array}$ \\
\hline $\begin{array}{l}\text { A1, A2, A4, } \\
\text { A5, C, D, D1, } \\
\text { E, F, F1, G2 e } \\
\text { G5. }\end{array}$ & $\begin{array}{c}\mathrm{A} 3, \mathrm{~A} 4, \mathrm{~A} 5, \mathrm{D}, \\
\mathrm{D} 1, \mathrm{E}, \mathrm{F}, \mathrm{F} 1, \\
\mathrm{H}^{* *}, \mathrm{G} \text { e G1. }\end{array}$ & $\begin{array}{l}\text { A4, A5, D, } \\
\text { D1, E, G, G1, } \\
\text { G3, G4 e G5. }\end{array}$ & $\begin{array}{c}\mathrm{A}, \mathrm{A} 3, \mathrm{~B}, \mathrm{C} 1, \mathrm{E}, \mathrm{F}, \mathrm{F} 1 \\
\mathrm{G}, \mathrm{G} 3 \mathrm{e} \text { G4 }\end{array}$ & $\begin{array}{c}\text { A, A5, F, F1, } \\
\text { E**, D, D1, } \\
\text { G2 e G5. }\end{array}$ & $\begin{array}{l}\mathrm{A} 1, \mathrm{~A} 4, \mathrm{C}, \\
\mathrm{C} 1, \mathrm{E}, \mathrm{F}^{* *}, \\
\mathrm{~F} 1 * *, \mathrm{G} 4 \mathrm{e} \\
\text { G5. }\end{array}$ \\
\hline $\begin{array}{l}\text { Introdução a } \\
\text { química }\end{array}$ & $\begin{array}{l}\text { Funções } \\
\text { inorgânicas }\end{array}$ & $\begin{array}{c}\text { Configuração } \\
\text { e eletrônica } \\
\text { dos elementos }\end{array}$ & Ligações químicas & $\begin{array}{l}\text { História da } \\
\text { química }\end{array}$ & $\begin{array}{l}\text { Linguagem } \\
\text { da química. }\end{array}$ \\
\hline $\begin{array}{c}\mathrm{A} 2, \mathrm{~A} 4, \mathrm{~A} 5, \mathrm{~B}, \\
\mathrm{C} 1, \mathrm{~F}^{* *}, \mathrm{~F} 1^{* *}, \\
\text { G e G2. }\end{array}$ & $\begin{array}{c}\text { A2, B, F, F1, G, } \\
\text { G1 e G5. }\end{array}$ & $\begin{array}{l}E^{* *}, F, G, G 1 \\
\text { G2, G3 e G5. }\end{array}$ & $\begin{array}{c}\mathrm{A}, \mathrm{E}, \mathrm{C}, \mathrm{G} 1, \mathrm{G} 2, \mathrm{G} 3 \mathrm{e} \\
\mathrm{G} 5 .\end{array}$ & $\begin{array}{c}\text { A2, A4, C, G2, } \\
\text { G4 e G5. }\end{array}$ & $\begin{array}{l}\text { A5, C, D1, } \\
\text { G, G1 e G4. }\end{array}$ \\
\hline
\end{tabular}




\begin{tabular}{|c|c|c|c|c|c|}
\hline $\begin{array}{l}\text { Propriedade } \\
\text { dos gases }\end{array}$ & $\begin{array}{c}\text { Balanceamento } \\
\text { de equação } \\
\text { química }\end{array}$ & $\begin{array}{l}\text { Reações } \\
\text { inorgânicas }\end{array}$ & $\begin{array}{c}\text { Fenômenos da } \\
\text { Natureza. }\end{array}$ & $\begin{array}{l}\text { Número de } \\
\text { oxidação }\end{array}$ & $\begin{array}{l}\text { Geometria } \\
\text { molecular e } \\
\text { polaridade }\end{array}$ \\
\hline $\begin{array}{c}\text { D, D1, E**, G } \\
\text { e G1. }\end{array}$ & D1, G, G1 e G4. & $\mathrm{G}, \mathrm{G} 1$ e $\mathrm{G} 4$ & B, D e G4. & A2, G e G1. & A, A2 e G4 \\
\hline Leis ponderais & $\begin{array}{c}\text { Classificação e } \\
\text { composição dos } \\
\text { materiais }\end{array}$ & Soluções & $\begin{array}{c}\text { Introdução a química } \\
\text { orgânica }\end{array}$ & $\begin{array}{l}\text { Conhecimento } \\
\text { científico e } \\
\text { senso comum }\end{array}$ & Ecossistema \\
\hline G e G4. & D1 e G4. & $\mathrm{C}^{* *}$ e D1. & $\mathrm{A} 1$ e A2. & C e D. & D2. \\
\hline Radioatividade & $\begin{array}{c}\text { A teoria sobre a } \\
\text { origem do } \\
\text { universo }\end{array}$ & Liofilização & $\begin{array}{l}\text { Deslocamento simples } \\
\text { (Reações químicas). }\end{array}$ & $\begin{array}{l}\text { Elementos } \\
\text { organógenos }\end{array}$ & $\begin{array}{l}\text { Propriedades } \\
\text { coligativas }\end{array}$ \\
\hline G5 & $\mathrm{C} 1$ & A4 & A2 & A2 & $\mathrm{C}^{* *}$ \\
\hline
\end{tabular}

Fonte: Dados coletados na pesquisa (2018-2020).

Quadro 3: Temas de química trabalhados nas turmas de segundo ano

\begin{tabular}{|c|c|c|c|c|c|}
\hline Soluções & $\begin{array}{l}\text { Equilíbrio } \\
\text { químico }\end{array}$ & $\begin{array}{l}\text { Reações } \\
\text { químicas }\end{array}$ & $\begin{array}{l}\text { Estados físicos e } \\
\text { Mudanças de } \\
\text { estado físico. }\end{array}$ & Termoquímica & Cinética química \\
\hline $\begin{array}{c}\mathrm{A}, \mathrm{A} 2^{* *}, \mathrm{~A} 4, \mathrm{~A} 5 \\
\mathrm{C}, \mathrm{D} *, \mathrm{D} 1, \mathrm{E}, \mathrm{F}^{*} \\
\mathrm{~F} 1, \mathrm{G}, \mathrm{G} 1^{* *} \\
\mathrm{G} 2^{* *}, \mathrm{G} 3 \mathrm{e} \mathrm{G} 5\end{array}$ & $\begin{array}{l}\text { C, D**, E, F, } \\
\text { F1, G, G1, G2, } \\
\text { G3 e G4. }\end{array}$ & $\begin{array}{l}\text { A, A3, A5, C, } \\
\text { D, D1, F1, G3, } \\
\text { G4 e H**. }\end{array}$ & $\begin{array}{l}\text { A1, A2, A3, A5, B, } \\
\text { E, F, F1 e } \mathrm{H}^{* *} .\end{array}$ & $\begin{array}{l}\text { C, F, F1, G, } \\
\text { G1**, G2**, G3 } \\
\text { e G4. }\end{array}$ & $\begin{array}{c}\mathrm{C}, \mathrm{F}^{* *}, \mathrm{~F} 1, \mathrm{G} \\
\mathrm{G} 1, \mathrm{G} 2 \\
\mathrm{G} 2 \text { e G4. }\end{array}$ \\
\hline Ligações químicas & $\begin{array}{l}\text { Propriedades } \\
\text { coligativas }\end{array}$ & $\begin{array}{l}\text { Unidades de } \\
\text { medidas e } \\
\text { grandezas }\end{array}$ & Atomística. & Eletroquímica & $\begin{array}{l}\text { Introdução a } \\
\text { química orgânica } \\
\text { e funções } \\
\text { orgânicas }\end{array}$ \\
\hline $\begin{array}{l}\mathrm{A} 2 * *, \mathrm{~A} 5, \mathrm{C} 1, \mathrm{D}, \\
\mathrm{D} 1, \mathrm{~B}, \mathrm{G} 2 \mathrm{e} \mathrm{G} 5 .\end{array}$ & $\begin{array}{l}\text { A2**, A4**, } \\
\text { A5, D, E**, F1, } \\
\text { G e G2. }\end{array}$ & $\begin{array}{l}\text { A, A3, C, D, } \\
\text { D1, G2, G3 e } \\
H^{* *} .\end{array}$ & $\begin{array}{l}\text { D, D1, C1, G2, G4 } \\
\text { e G5. }\end{array}$ & $\begin{array}{l}\text { A2, A4, A5, G, } \\
\text { G2 e G5. }\end{array}$ & $\begin{array}{l}\text { A, A3, A1, A2, } \\
\text { C1, G4 e G5. }\end{array}$ \\
\hline $\begin{array}{l}\text { Funções } \\
\text { inorgânicas }\end{array}$ & $\begin{array}{l}\text { Configuração } \\
\text { eletrônica }\end{array}$ & Misturas & Termodinâmica & Substâncias & $\begin{array}{l}\text { Balanceamento } \\
\text { das equações } \\
\text { químicas }\end{array}$ \\
\hline $\mathrm{A}^{* *}, \mathrm{~A} 2, \mathrm{~B}$ e $\mathrm{G} 5$. & $\begin{array}{l}\text { A2, C1, G4 e } \\
\text { G5. }\end{array}$ & $\begin{array}{l}\text { A5, G, G1 e } \\
\text { G3. }\end{array}$ & $\mathrm{G}, \mathrm{G} 1, \mathrm{G} 2$ e G3. & $\begin{array}{l}\text { A1, A3, E, D1 e } \\
\text { G2. }\end{array}$ & A, D, D1 e G5. \\
\hline $\begin{array}{l}\text { A energia e as } \\
\text { transformações da } \\
\text { matéria }\end{array}$ & Tabela periódica. & $\begin{array}{l}\text { Diagrama de } \\
\text { fases }\end{array}$ & Dispersões & $\begin{array}{l}\text { Classificação e } \\
\text { composição dos } \\
\text { materiais. }\end{array}$ & $\begin{array}{l}\text { Linguagem da } \\
\text { química }\end{array}$ \\
\hline $\mathrm{A} 1, \mathrm{~F}, \mathrm{~F} 1 \mathrm{e} \mathrm{G} 4$. & $\begin{array}{l}\text { A3, C1, G4 e } \\
\text { G5. }\end{array}$ & A4, A5 e E. & D, F e F1. & C, D e D1. & A3, A5 e D1. \\
\hline
\end{tabular}




\begin{tabular}{|c|c|c|c|c|c|}
\hline Estequiometria & $\begin{array}{l}\text { Propriedades dos } \\
\text { gases }\end{array}$ & $\begin{array}{l}\text { Modelos } \\
\text { atômicos }\end{array}$ & Radioatividade & $\begin{array}{l}\text { Propriedade dos } \\
\text { metais }\end{array}$ & $\begin{array}{l}\text { Propriedades da } \\
\text { matéria }\end{array}$ \\
\hline C e G5. & D1 e G5. & C1 e G4. & G e G2. & A2 e B. & A3, C e D. \\
\hline Polímeros & $\begin{array}{l}\text { Química, } \\
\text { tecnologia e } \\
\text { sociedade }\end{array}$ & Elementos & $\begin{array}{l}\text { Geometria } \\
\text { molecular }\end{array}$ & $\begin{array}{l}\text { Propriedades da } \\
\text { água. }\end{array}$ & $\begin{array}{l}\text { Constante de } \\
\text { Avogadro. }\end{array}$ \\
\hline C1. & D1. & A2 e A3. & A2. & D. & C. \\
\hline
\end{tabular}

Fonte: Dados coletados na pesquisa (2018-2020).

Quadro 4: Temas de química trabalhados nas turmas dos terceiros anos do EM.

\begin{tabular}{|c|c|c|c|c|c|}
\hline $\begin{array}{l}\text { Classificação do } \\
\text { Carbono e } \\
\text { cadeias } \\
\text { carbônicas }\end{array}$ & Funções orgânicas & $\begin{array}{l}\text { Nomenclatura de } \\
\text { Compostos } \\
\text { orgânicos }\end{array}$ & $\begin{array}{l}\text { Propriedades do } \\
\text { Carbono }\end{array}$ & $\begin{array}{l}\text { Ligações } \\
\text { químicas }\end{array}$ & $\begin{array}{c}\text { Introdução a } \\
\text { química orgânica }\end{array}$ \\
\hline $\begin{array}{c}\mathrm{A}, \mathrm{A} 2, \mathrm{~A} 4, \mathrm{C}, \mathrm{D} \\
\mathrm{F}, \mathrm{F} 1, \mathrm{G}, \mathrm{G} 2 \mathrm{e} \\
\mathrm{G} .4\end{array}$ & $\begin{array}{l}\text { A2**, A4, C, D, F, } \\
\text { F1, G**, G2** e } \\
\text { G4. }\end{array}$ & $\begin{array}{l}\text { A, A2, D, F, F1, } \\
\text { G, G2 e G4. }\end{array}$ & $\begin{array}{l}\mathrm{A}, \mathrm{C}, \mathrm{D}, \mathrm{F}, \mathrm{F} 1, \mathrm{G}, \\
\mathrm{G} 2^{* *} \text { e } \mathrm{G} 4\end{array}$ & $\begin{array}{l}\text { A2, A4, B, C, D, } \\
\text { G** e G2**. }\end{array}$ & $\begin{array}{c}\mathrm{A} 2, \mathrm{~A} 4, \mathrm{C}, \mathrm{F}, \mathrm{F} 1 \mathrm{e} \\
\mathrm{G} 4 .\end{array}$ \\
\hline Isomeria & Cisão de ligações & $\begin{array}{l}\text { Carboidratos, } \\
\text { lipídios e } \\
\text { proteínas }\end{array}$ & $\begin{array}{l}\text { Formas de } \\
\text { representação de } \\
\text { moléculas } \\
\text { orgânicas }\end{array}$ & Polímeros & $\begin{array}{l}\text { Reações químicas } \\
\text { / orgânicas }\end{array}$ \\
\hline $\begin{array}{l}\text { A2, C, G, G2 e } \\
\text { G4. }\end{array}$ & $\mathrm{F}, \mathrm{F} 1, \mathrm{G}$ e $\mathrm{G} 2$ & $\mathrm{C}, \mathrm{D}, \mathrm{G}$ e G2. & $\mathrm{A}, \mathrm{A} 2, \mathrm{~F}$ e $\mathrm{F} 1$. & $\mathrm{C}, \mathrm{G}$ e G2. & $\mathrm{G}, \mathrm{G} 2$ e G4. \\
\hline $\begin{array}{l}\text { Propriedades dos } \\
\text { metais }\end{array}$ & \begin{tabular}{|l} 
Funções \\
inorgânicas
\end{tabular} & Oxirredução & $\begin{array}{l}\text { Geometria } \\
\text { molecular }\end{array}$ & Séries orgânicas & $\begin{array}{l}\text { História da } \\
\text { química orgânica }\end{array}$ \\
\hline A2, B e C. & $\mathrm{A} 2$ e B. & $\mathrm{A} 2$ e $\mathrm{C}$. & A 2 e A4. & G e G2. & A4 e G4. \\
\hline $\begin{array}{l}\text { Química orgânica } \\
\text { e a } \\
\text { transformação da } \\
\quad \text { vida }\end{array}$ & $\begin{array}{l}\text { Estabilidade e } \\
\text { regra do octeto }\end{array}$ & Síntese orgânica. & Radioatividade & $\begin{array}{l}\text { Propriedades dos } \\
\text { compostos } \\
\text { orgânicos. }\end{array}$ & Soluções \\
\hline D. & A 2. & C. & G4. & G4. & A. \\
\hline
\end{tabular}

Fonte: Dados coletados na pesquisa (2018-2020).

Se considerarmos os cinco temas mais trabalhados nos primeiros anos, estes seguem a base da proposta pelas OC de MT, que iniciam o currículo de química sobre os alicerces da constituição da matéria, suas propriedades e transformações e sugere um aprofundamento nos anos seguintes (Mato Grosso, 2010). 
Umas das peculiaridades percebidas no quadro 2, foi o ensino de radioatividade na unidade G5, por se tratar de uma turma de EJA. O mais intrigante é que o conteúdo aparece como ministrado nas primeiras aulas com a turma e por ser um conceito que exige bastante abstração por parte dos estudantes, geralmente é ensinado nos momentos finais do segundo ano ou no terceiro ano. O diário da turma D1 apresentou diversos registros de conteúdos, sendo trabalhados de forma contextualizada. A unidade $\mathrm{C} 1$, trabalhou a teoria de origem do universo, um tema, que pode ser polêmico para essa modalidade, mas também necessário, que inclusive pode desenvolver criticidade nos estudantes ou na pior das hipóteses, rejeição. Embora A1 e A3 se tratarem da mesma modalidade (EJA) e serem da mesma escola, é notória a diferença entre os conteúdos registrados, evidenciando o quanto estes podem ser diferentes, independente do meio sociocultural.

Ainda sobre o quadro 2, foi percebido que a unidade A4 possui em seus registros maiores diferenças nos conteúdos do primeiro ano, em relação as outras. A3 dedicou boa parte do primeiro semestre a detalhar o tema sobre rótulos e embalagens. A unidade A3 trabalhou uma maior diversidade de conteúdos, como exemplo os conteúdos que geralmente são trabalhados no segundo ano regular como substâncias, soluções e misturas. A escola F, apesar de possuir duas modalidades de Ensino Médio, apresentou conteúdos similares em ambas no primeiro ano do Ensino Médio, isso pode ser justificado pelo fato da disciplina de química ter sido ministrada pelo mesmo professor.

O tema mais trabalhado nos segundos anos do Ensino Médio (quadro 3), foi soluções. Este é, geralmente, o primeiro tema abordado na maioria dos livros didáticos do segundo ano. Damasceno, Wartha \& Silva, (2009), em sua pesquisa também relata o quanto os conteúdos abordados em sala de aula têm sido dependentes dos livros didáticos e essa metodologia muitas vezes acaba por reforçar currículos lineares e fragmentados, com atividades rígidas e mecânicas que não promovem aprendizagem significativa.

O conteúdo soluções é seguido pelos de reações químicas e suas propriedades de equilíbrio, cinética e calor. As propriedades físicas e químicas também se destacaram. Compreende-se que temas como linguagem da química, constante de Avogadro, estequiometria, diagramas de fases e propriedades da água e dos metais podem terem sido trabalhados dentro de outras temáticas por mais escolas. A unidade G3, em alguns casos, trabalhou determinados conteúdos em mais de um momento (momentos diferentes). 
O quantitativo de turmas de terceiro ano (quadro 4) é menor em relação aos outros anos, primeiro, porque as turmas de EJA, com exceção da B, possuíam modalidade de dois anos, por isso foram incluídas nos quadros 2 e 3. Segundo, porque nenhuma unidade indígena e também a escola E, ofertou terceiro ano em 2017, pelo que foi informado por secretários, isso ocorreu devido à falta de demanda.

Nos terceiros anos os compostos de carbono (orgânicos) foram tema central quase que unanimemente. As diferenças pairaram mais sobre a questão do aprofundamento dos conteúdos do que drásticas diferenças em si. Compreende-se que a nomenclatura dos compostos orgânicos pode ter sido ministrada na categoria de funções orgânicas também. As unidades que mais destoaram das demais foram a A e A2, revendo alguns conteúdos já estudados em anos anteriores. E a unidade G4 com o estudo da radioatividade. As unidades F e F1, apresentaram bastante similaridades nos conteúdos registrados, possivelmente devido a disciplina ter sido ministrada pelo mesmo professor.

Os temas trabalhados, em alguns casos, mudaram bastante de uma escola para a outra, até mesmo em relação aos bimestres em que os temas foram trabalhados. Isso pode ter gerado descontinuidade lógica de conteúdos para os estudantes, que necessitam de transferência entre estas escolas, mas o fato é que esta é uma consequência difícil de ser sanada em qualquer situação de mobilidade.

Herber (2007) e Damasceno, Wartha \& Silva (2009), relatam em suas pesquisas que os professores ainda têm se mostrado muito conteudistas e presos a sequências pré estabelecidas. Muitos desses entraves podem ser causados por inseguranças dos professores frente aos costumes já estabelecidos.

Muito se tem discutido a ideia de que não é necessário ensinar uma grande quantidade de conteúdos, mas que se ensine com qualidade. Ao ensinar menos conteúdos se torna mais fácil ensiná-los de forma investigativa, minuciosa e contextualizada, aprofundando de forma gradual conforme os estudantes forem se desenvolvendo (Oki \& Moradillo, 2008). Mas isso não significa que aulas conteudistas não possam promover aprendizagens significativas. Como pode ser observado nos quadros 2, 3 e 4, quantidade de conteúdos trabalhados apresentou diferenças. Consequentemente, acredita-se que tenha ocasionado diferentes níveis de aprendizagem. Não houve acréscimo de conteúdos, quando considerada a tríade 'propriedade-constituiçãotransformação da matéria' já que esta abrange praticamente toda a química e é a base desta 
disciplina também nas OC (Mato Grosso, 2010). Os temas socioculturais foram enquadrados nas abordagens interdisciplinares. A maioria dos temas contextualizados e interdisciplinares foram de relevância para a comunidade local.

Percebeu-se que os conteúdos ministrados, geralmente iniciaram semelhantemente, o que destoou é que conforme os meses foram passando, algumas unidades não conseguiram progredir como outras, como se houvesse uma tentativa inicial de se cumprir o currículo, mas devidos a interferências, como a dificuldade dos estudantes (justificada aqui pela repetição do mesmo conteúdo por várias aulas nos registros) houvesse impedido de seguir a diante com os conteúdos, provocando o não cumprimento completo das OC.

A segunda categoria é referente a Contextualização, ou seja, a relação dos conteúdos com a realidade ou ainda a aplicações práticas do conceito. A terceira categoria está relacionada a interdisciplinaridade, ou seja, quais conteúdos relacionam a química com outras áreas do conhecimento. Nos quadros 5, 6 e 7 são detalhadas as contextualizações registradas nos diários e os conteúdos interdisciplinares.

Quadro 5: Contextualização e Interdisciplinaridade nas turmas do primeiro ano

\begin{tabular}{|c|c|c|}
\hline & Contextualização/aplicações práticas do conceito & Interdisciplinaridade \\
\hline A & Nenhuma registrada. & Elementos organógenos, Química cidadã. \\
\hline A1 & $\begin{array}{l}\text { Poluição do solo e saúdes dos seres vivos. A } \\
\text { química no cotidiano (reciclagem, biodiesel, } \\
\text { plásticos). Substâncias químicas presentes no dia a } \\
\text { dia. }\end{array}$ & $\begin{array}{l}\text { Poluição do solo e saúde dos seres vivos. Estados } \\
\text { físicos da matéria e as mudanças entre eles. } \\
\text { Energia. }\end{array}$ \\
\hline A2 & Química e cidadania. & Estados físicos da matéria. Densidade. \\
\hline A3 & Rótulos e embalagens.** O que fazer com o lixo. & Grandezas. O que fazer com o lixo. \\
\hline A4 & $\begin{array}{l}\text { Química artificial ou natural. Química pode } \\
\text { proporcionar qualidade de vida. Contaminação } \\
\text { química no meio ambiente. Alguns íons presentes } \\
\text { na alimentação. }\end{array}$ & $\begin{array}{l}\text { Contaminação química do meio ambiente. } \\
\text { Grandezas. Estados de agregação da matéria. } \\
\text { Liofilização. A natureza elétrica da matéria. }\end{array}$ \\
\hline A5 & $\begin{array}{l}\text { A química nas receitas caseiras. Química e cidadania. } \\
\text { Diálogo sobre a composição dos alimentos. } \\
\text { Mudanças de estados físicos da água. } \\
\text { Conversa informal sobre ponto de ebulição. }\end{array}$ & Estados físicos da matéria. Unidades de medidas. \\
\hline
\end{tabular}




\begin{tabular}{|c|c|c|}
\hline B & $\begin{array}{l}\text { Rótulo e embalagens. Remédio e veneno, proporções } \\
\text { e quantidades. Materiais ácidos e básicos. Lixo. } \\
\text { Poluição ambiental. Agrotóxicos. Dengue. Doenças } \\
\text { profissionais. A importância da separação de } \\
\text { materiais em misturas para a sociedade. }\end{array}$ & $\begin{array}{l}\text { Mudanças de estado físico. Fenômenos naturais. } \\
\text { Quantidades e proporções. Separação de misturas. } \\
\text { Olimpíada de matemática. Letramento estatístico. } \\
\text { Lixo. Agrotóxicos. Poluição ambiental. Fórum de } \\
\text { diagnóstico da realidade escolar. Cultura em todo } \\
\text { esporte (Palestra). Bazar e gincana. Consciência } \\
\text { negra. Novembro azul, o fim do preconceito. } \\
\text { Confraternização. }\end{array}$ \\
\hline $\mathrm{C}$ & $\begin{array}{l}\text { Química, Tecnologia e sociedade. Consumismo } \\
\text { Reciclagem. O uso de agrotóxico na comunidade. } \\
\text { Química dos oceanos }\end{array}$ & $\begin{array}{l}\text { Tecnologia e sociedade. Conhecimento científico e } \\
\text { senso comum. O uso de agrotóxicos na } \\
\text { comunidade. Lixo. Reciclagem. Consumo } \\
\text { sustentável. Densidade. Propriedades Coligativas. }\end{array}$ \\
\hline $\mathrm{C} 1$ & $\begin{array}{l}\text { A química em nosso cotidiano. Química e } \\
\text { agricultura. O solo e a agricultura. Insumos agrícolas. } \\
\text { Os principais tipos de solos do Brasil. Os elementos } \\
\text { químicos e os vegetais. Produções de alimentos. } \\
\text { Alimentos transgênicos. }\end{array}$ & $\begin{array}{l}\text { Transformações da matéria. Fases de um sistema e } \\
\text { processos de separação. Solos. Agricultura. Teoria } \\
\text { sobre a origem do Universo. Produção de alimentos. } \\
\text { Insumos agrícolas. Alimentos transgênicos. }\end{array}$ \\
\hline D & $\begin{array}{l}\text { Química, tecnologia e sociedade. Poluição } \\
\text { atmosférica e suas consequências }\end{array}$ & $\begin{array}{l}\text { Química, tecnologia e sociedade. Conhecimento } \\
\text { científico e senso comum. Poluição atmosférica e } \\
\text { aquecimento global. Unidades de medida. } \\
\text { Grandezas. Separação de misturas. Química, } \\
\text { tecnologia e sociedade. Densidade. Estudo dos } \\
\text { gases. }\end{array}$ \\
\hline D1 & $\begin{array}{l}\text { Química, tecnologia e sociedade. Os materiais de } \\
\text { ontem e de hoje. Sabões e detergentes. Poluição } \\
\text { atmosférica, aquecimento global e efeito estufa. } \\
\text { Desmatamento: a falta de água inicia com a } \\
\text { diminuição das florestas. O futuro dos materiais que } \\
\text { utilizamos. Obtenção e uso dos recursos energéticos. } \\
\text { Petróleo e seus derivados. Obtenção e uso dos } \\
\text { recursos minerais. }\end{array}$ & $\begin{array}{l}\text { Química, tecnologia e sociedade. Propriedades } \\
\text { físicas da matéria. A estrutura dos átomos. } \\
\text { Propriedades dos gases. Unidades de medida. } \\
\text { Poluição atmosférica, aquecimento global e efeito } \\
\text { estufa. Desmatamento: a falta de água inicia com a } \\
\text { diminuição das florestas. O futuro dos materiais que } \\
\text { utilizamos. Obtenção e uso dos recursos } \\
\text { energéticos. Petróleo e seus derivados. Obtenção e } \\
\text { uso dos recursos minerais. }\end{array}$ \\
\hline D2 & $\begin{array}{l}\text { Consumismo. Medicina científica e medicina } \\
\text { popular. Catálogo dos anciões da comunidade com } \\
\text { diversas práticas e conhecimentos de medicamentos } \\
\text { de origem vegetal e animal usados na comunidade } \\
\text { indígena local. Produção de medicamentos naturais a } \\
\text { partir do coco de piaçava para o consumo interno na } \\
\text { comunidade. }\end{array}$ & $\begin{array}{l}\text { Consumismo. Medicina científica e medicina } \\
\text { popular. Ecossistema. }\end{array}$ \\
\hline $\mathrm{E}$ & $\begin{array}{l}\text { Poluição atmosférica. Química na agricultura e } \\
\text { descarte adequado das embalagens de fertilizantes. } \\
\text { Produção de alimentos. Biocombustíveis. }\end{array}$ & $\begin{array}{l}\text { Química, tecnologia e sociedade. Propriedades da } \\
\text { matéria. Separação de misturas. Propriedades dos } \\
\text { gases. Química na agricultura. Descartes de } \\
\text { embalagens de fertilizantes. Alimentos } \\
\text { transgênicos. Biocombustíveis. Estudo dos gases. }\end{array}$ \\
\hline $\mathrm{F}$ & A contribuição da química para a ciência. & $\begin{array}{l}\text { Química, tecnologia e sociedade. História da } \\
\text { química. Unidades de medida. Propriedades físicas. }\end{array}$ \\
\hline
\end{tabular}




\begin{tabular}{|c|c|c|}
\hline $\mathrm{F} 1$ & A contribuição da química para a ciência. & $\begin{array}{l}\text { Química, tecnologia e sociedade. História da } \\
\text { química. Unidades de medida. Propriedades físicas. }\end{array}$ \\
\hline $\mathrm{G}$ & Materiais do nosso cotidiano. & $\begin{array}{l}\text { Unidades de medida. Estrutura atômica. } \\
\text { Propriedades dos gases. }\end{array}$ \\
\hline G1 & Materiais do nosso cotidiano. & $\begin{array}{l}\text { Unidades de medida. Estrutura atômica. } \\
\text { Propriedades dos gases }\end{array}$ \\
\hline G2 & Química na sociedade. Tecnologia: fruto da ciência. & $\begin{array}{l}\text { História da química. Química, Tecnologia e } \\
\text { sociedade. Mudanças de estado físico. }\end{array}$ \\
\hline G3 & $\begin{array}{l}\text { Rótulo e embalagens. Remédio e veneno, proporções } \\
\text { e quantidades. O fim dos materiais que utilizamos. } \\
\text { Exploração do petróleo. Doenças profissionais. } \\
\text { Consumo sustentável. Medicamentos e as marcas. } \\
\text { Fármaco, Agrotóxicos. Fitoterápicos. }\end{array}$ & $\begin{array}{l}\text { Rótulos e embalagens. Destino dos materiais que } \\
\text { utilizamos. Exploração do petróleo. Doenças } \\
\text { profissionais. Consumo sustentável. } \\
\text { Medicamentos. Medicamentos: Marca registrada, } \\
\text { genéricos e similares. Agrotóxicos. }\end{array}$ \\
\hline G4 & $\begin{array}{l}\text { Métodos comum de separação e purificação de } \\
\text { substâncias: Filtração, decantação, destilação e } \\
\text { adsorção. }\end{array}$ & $\begin{array}{l}\text { Estrutura atômica. Geometria molecular. } \\
\text { Fenômenos físicos. }\end{array}$ \\
\hline G5 & Química e a evolução da sociedade. & Química e a evolução da sociedade. Radioatividade. \\
\hline $\mathrm{H}$ & $\begin{array}{l}\text { Mudanças de estado físico (água sólida (gelo), água } \\
\text { líquida). Descobrindo a massa de objetos através da } \\
\text { comparação de objetos com massa conhecida com } \\
\text { objetos de massa desconhecida. Ilustração de vários } \\
\text { objetos medidos com medida padrão (quilograma). } \\
\text { Os materiais que sofrem transformações no lixo e os } \\
\text { que não sofrem. Mudanças de cor, cheiro e da } \\
\text { aparência. }\end{array}$ & $\begin{array}{l}\text { Estados físicos e mudanças. Unidades de medidas e } \\
\text { grandezas. Os lixos que sofrem uma série de } \\
\text { transformações. }\end{array}$ \\
\hline
\end{tabular}

Fonte: Dados coletados na pesquisa (2018-2020).

Quadro 6: Contextualização e Interdisciplinaridade nas turmas de segundo ano

\begin{tabular}{|c|c|c|}
\hline & $\begin{array}{l}\text { Contextualização/relação com } \\
\text { realidade/aplicações práticas do conceito }\end{array}$ & a Interdisciplinaridade \\
\hline A & Nenhum & Unidades de medidas. \\
\hline A1 & $\begin{array}{l}\text { Poluição do solo e saúde dos seres vivos. A química } \\
\text { no cotidiano: Reciclagem, biodiesel e plásticos. } \\
\text { Substâncias químicas presentes no dia a dia }\end{array}$ & $\begin{array}{l}\text { Poluição do solo e saúde dos seres vivos. } \\
\text { A química no cotidiano: Reciclagem, biodiesel e } \\
\text { plásticos. Estados físicos da matéria e mudanças de } \\
\text { estado físico da matéria. }\end{array}$ \\
\hline A2 & $\begin{array}{l}\text { Aumentando a temperatura da água sem aquecê-la. } \\
\text { Usos dos ácidos, bases, ácidos carboxílicos, aminas } \\
\text { e sais. }\end{array}$ & $\begin{array}{l}\text { Diagrama de fases. Propriedades coligativas. } \\
\text { Geometria molecular. }\end{array}$ \\
\hline
\end{tabular}




\begin{tabular}{|c|c|c|}
\hline A3 & $\begin{array}{l}\text { O descarte dos materiais que utilizamos, como era e } \\
\text { como é. O que acontece como os materiais lançados } \\
\text { no meio ambiente. O que fazer com o lixo. Poluentes } \\
\text { do ar. Óleos vegetais e derivados do petróleo. } \\
\text { Fertilizantes e pesticidas. Por que detergente limpa e } \\
\text { por que polui. }\end{array}$ & $\begin{array}{l}\text { Estados físicos da matéria. Unidades de medidas e } \\
\text { grandezas. Propriedades da matéria. Descarte de } \\
\text { materiais e o meio ambiente. Poluição do ar. Óleos } \\
\text { vegetais e derivados do petróleo. Fertilizantes e } \\
\text { pesticidas. }\end{array}$ \\
\hline A4 & $\begin{array}{l}\text { Reconhecendo soluções aquosas no dia a dia. Uso } \\
\text { de anticongelantes em veículos. }\end{array}$ & $\begin{array}{l}\text { Propriedades coligativas. Estudo de gráfico: Pressão } \\
\text { e vapor. }\end{array}$ \\
\hline A5 & $\begin{array}{l}\text { Interpretação de rótulos. } \\
\text { Leitura sobre experiências feitas em laboratório e } \\
\text { noções práticas com materiais caseiros. } \\
\text { Aumentando a temperatura da água sem aquecê-la }\end{array}$ & $\begin{array}{l}\text { Estados físicos da matéria e mudanças de estados } \\
\text { físicos. }\end{array}$ \\
\hline & $\begin{array}{l}\text { Interpretação e construção de gráficos sobre fases da } \\
\text { água. } \\
\text { Relatos de temperatura do dia a dia. } \\
\text { Processos de separação do sal da água. }\end{array}$ & \\
\hline $\mathrm{C}$ & $\begin{array}{l}\text { Evitando o desperdício. Produtos químicos } \\
\text { domésticos: Perigo disfarçado. Poluição das águas. } \\
\text { Tratamento da água e saneamento básico. } \\
\text { Transformações de energia. }\end{array}$ & $\begin{array}{l}\text { Grandezas. Constante de Avogadro. Entropia. } \\
\text { Transformações de energia. Fontes de energia. } \\
\text { Poluição, tratamento das águas e saneamento. }\end{array}$ \\
\hline $\mathrm{C} 1$ & $\begin{array}{l}\text { Tipos de solo. O solo e a agricultura. As } \\
\text { transformações da vida. Petróleo: Fonte de } \\
\text { hidrocarbonetos. Alimentos e funções orgânicas. } \\
\text { Química da saúde e da beleza. Plásticos, fibras e } \\
\text { borrachas. O plástico e o ambiente. }\end{array}$ & $\begin{array}{l}\text { Tipos de solos. Os estados energéticos do elétron. O } \\
\text { solo e a agricultura. As transformações da vida. } \\
\text { Alimentos e funções orgânicas. Química da saúde e } \\
\text { da beleza. O plástico e o ambiente. }\end{array}$ \\
\hline $\mathrm{D}$ & $\begin{array}{l}\text { Propriedades da água. Poluição das águas. O } \\
\text { equilíbrio das cavernas. Estrutura geológica: relevos } \\
\text { e solos. }\end{array}$ & $\begin{array}{l}\text { Classificação e composição dos materiais. } \\
\text { Unidades de medidas. Propriedades da água. } \\
\text { Solubilidade Propriedades coligativas. Estrutura } \\
\text { geológica, relevos e solos. }\end{array}$ \\
\hline D1 & $\begin{array}{l}\text { Química, tecnologia e sociedade. Os materiais de } \\
\text { ontem e hoje. Sabões e detergentes. Poluição } \\
\text { atmosférica, aquecimento global e efeito estufa. } \\
\text { Desmatamento: a falta de água inicia com a } \\
\text { diminuição das florestas. O futuro dos materiais que } \\
\text { utilizamos. Obtenção e uso dos recursos energéticos. } \\
\text { Petróleo e seus derivados. Obtenção e uso dos } \\
\text { recursos minerais. }\end{array}$ & $\begin{array}{l}\text { Química, tecnologia e sociedade. } \\
\text { A estrutura dos átomos. } \\
\text { Propriedades dos gases. } \\
\text { Unidades de medida. } \\
\text { Poluição atmosférica, aquecimento global e efeito } \\
\text { estufa. } \\
\text { Desmatamento: a falta de água inicia com a } \\
\text { diminuição das florestas. } \\
\text { O futuro dos materiais que utilizamos. } \\
\text { Obtenção e uso dos recursos energéticos. } \\
\text { Petróleo e seus derivados. } \\
\text { Obtenção e uso dos recursos minerais. }\end{array}$ \\
\hline \multirow{2}{*}{ E } & $\begin{array}{l}\text { Elementos químicos do dia a dia. } 100 \text { elementos } \\
\text { indispensáveis. }\end{array}$ & $\begin{array}{l}\text { Solubilidade. Propriedades coligativas. Diagrama de } \\
\text { fases. }\end{array}$ \\
\hline & $\begin{array}{l}\text { A energia e as transformações da matéria. Estados } \\
\text { físicos. Medidas da quantidade de calor }\end{array}$ & $\begin{array}{l}\text { A Energia e as transformações da matéria. } \\
\text { Entalpia nas mudanças de estado físico. Cinética. }\end{array}$ \\
\hline $\mathrm{F} 1$ & $\begin{array}{l}\text { A energia e as transformações da matéria. } \\
\text { Catalisadores na indústria. }\end{array}$ & Energia e as transformações da matéria. Cinética. \\
\hline
\end{tabular}




\begin{tabular}{|c|c|c|}
\hline G & Nenhuma registrada. & Propriedades coligativas. \\
\hline G1 & Nenhuma registrada. & $\begin{array}{l}\text { Densidade. Termodinâmica. Cinética. Solubilidade. } \\
\text { Radioatividade. }\end{array}$ \\
\hline G2 & Nenhuma registrada. & $\begin{array}{l}\text { Densidade. } \\
\text { Termodinâmica. }\end{array}$ \\
\hline G3 & Nenhuma registrada. & $\begin{array}{l}\text { Unidades de medida. Densidade. Termodinâmica. } \\
\text { Calor. }\end{array}$ \\
\hline G4 & $\begin{array}{l}\text { Aspectos químicos e implicações ambientais. EnergiaA } \\
\text { e organismos vivos: Fotossíntese, fermentação ee } \\
\text { oxidação completa da glicose. O equilíbrio químico eo } \\
\text { a produção de amônia. A utilização das P P } P \\
\text { transformações químicas na obtenção de energia. A } \\
\text { cinética química e a conservação de alimentos. }\end{array}$ & $\begin{array}{l}\text { Aspectos químicos e implicações ambientais. Energia } \\
\text { organismos vivos: Fotossíntese, fermentação e } \\
\text { oxidação completa da glicose. } \\
\text { Partículas subatômicas. }\end{array}$ \\
\hline G5 & Nenhuma registrada. & Estudo dos gases. \\
\hline $\mathrm{H}$ & $\begin{array}{l}\text { Mudanças de estado físico (água sólida "gelo", águaE } \\
\text { líquida). Descobrindo a massa de objetos através dag } \\
\text { comparação de objetos com massa conhecida comtt } \\
\text { objetos de massa desconhecida. Ilustração de vários } \\
\text { objetos medidos com medida padrão que é o } \\
\text { quilograma. Os materiais que sofrem transformações } \\
\text { no lixo os que não sofrem. Mudanças de cor, cheiro } \\
\text { e da aparência. Matériasprimas que sofrem } \\
\text { transformações com o passar do tempo. }\end{array}$ & $\begin{array}{l}\text { Estados físicos e mudanças. Unidades de medidas e } \\
\text { grandezas. Os lixos que sofrem uma série de } \\
\text { transformações. }\end{array}$ \\
\hline
\end{tabular}

Fonte: Dados coletados na pesquisa (2018-2020).

Quadro 7: Contextualização e Interdisciplinaridade nas turmas de terceiro ano

\begin{tabular}{|c|c|c|}
\hline & $\begin{array}{l}\text { Contextualização/relação com a realidade/aplicações práticas do } \\
\text { conceito }\end{array}$ & Interdisciplinaridade \\
\hline A & Nenhuma registrada. & Nenhuma registrada. \\
\hline A2 & Nenhuma registrada. & Nenhuma registrada. \\
\hline A4 & Bebidas alcoólicas e seus riscos à saúde. & $\begin{array}{l}\text { História da química orgânica. Bebidas } \\
\text { alcoólicas e os riscos à saúde. }\end{array}$ \\
\hline $\mathrm{C}$ & $\begin{array}{l}\text { Indústria química e sociedade. Química da conservação de } \\
\text { alimentos. Alimentos e as funções orgânicas. Os plásticos e o } \\
\text { ambiente. Metais: materiais do nosso dia a dia. }\end{array}$ & \\
\hline $\mathrm{D}$ & $\begin{array}{l}\text { A química orgânica e a transformação da vida. A química e os } \\
\text { alimentos. Refinamento do petróleo. Alimentos e as funções } \\
\text { orgânicas. Onde estão presentes os ácidos carboxílicos e ésteres. }\end{array}$ & $\begin{array}{l}\text { A química e os alimentos. A química } \\
\text { orgânica e a transformação da vida. } \\
\text { Química da saúde e da beleza. } \\
\text { Fármacos, venenos e cosméticos. }\end{array}$ \\
\hline
\end{tabular}




\begin{tabular}{|c|c|c|}
\hline $\mathrm{F}$ & $\begin{array}{l}\text { Aplicação de álcoois, enóis, fenóis, ésteres, aldeídos, cetonas, } \\
\text { ácidos carboxílicos, éteres. }\end{array}$ & Nenhuma registrada. \\
\hline F1 & $\begin{array}{l}\text { Aplicação de álcoois, enóis, fenóis, ésteres, aldeídos, cetonas, } \\
\text { ácidos carboxílicos, éteres. }\end{array}$ & Nenhuma registrada. \\
\hline G & Obtenção de alcanos, alcenos, alcinos e alcadienos. & Bioquímica. \\
\hline $\mathrm{G} 2$ & Obtenção de alcanos, alcenos, alcinos e alcadienos. & Bioquímica. \\
\hline G4 & $\begin{array}{l}\text { Importância dos compostos orgânicos. Radioatividade: Aplicações } \\
\text { práticas no cotidiano e no sistema produtivo. Vantagens e } \\
\text { desvantagens da energia nuclear em relação a outras fontes } \\
\text { energéticas. Transformações nucleares naturais e artificiais. } \\
\text { Utilização do raio-X. Problemas ambientes decorrentes do } \\
\text { emprego de materiais radioativos. Problemas ambientais } \\
\text { associados ao uso dos plásticos e alternativas para minimizá-los. } \\
\text { Sabões e detergentes. Biodegradabilidade. Indústria petroquímica, } \\
\text { petróleo e seus derivados. }\end{array}$ & $\begin{array}{l}\text { Importância dos compostos orgânicos. } \\
\text { Radioatividade Problemas ambientes } \\
\text { decorrentes do emprego de materiais } \\
\text { radioativos. Problemas ambientais } \\
\text { associados ao uso dos plásticos e } \\
\text { alternativas para minimizá-los. } \\
\text { Biodegradabilidade. } \\
\text { petroquímica, petróleo e seus } \\
\text { derivados. História da química } \\
\text { orgânica. }\end{array}$ \\
\hline
\end{tabular}

Fonte: Dados coletados na pesquisa (2018-2020).

No primeiro ano, a unidade G5 registrou pouca contextualização, algo incomum e não recomendado especificamente para a modalidade EJA. A unidade D2 enfatizou a importância da aprendizagem das tradições que envolvem química, no caso a medicinal. Os temas relacionados a agricultura foram destaque no quesito contextualização na unidade $\mathrm{C} 1$, uma metodologia bem aplicada a essa turma EJA/rural, inclusive essa prática é bastante incentivada pelas OC (Mato Grosso, 2010). A unidade A5 explanou uma quantidade de conteúdos maior que as demais turmas de EJA, porém relatou menos contextualizações, indo na contramão das metodologias sugeridas pela maioria dos autores que falam sobre o ensino da EJA. Por meio da análise dos diários, é possível sugerir que os professores ainda têm enfrentado dificuldades em relacionar a maioria dos conteúdos com o cotidiano do aluno e essa dificuldade também sido percebida em escolas de outros estados (Herber, 2007).

Com exceção das unidades G1 e G3, do quadro 5, as demais unidades de EJA foram destaque no quesito contextualização e este fato é bem quisto nessa modalidade, inclusive fundamental para uma aprendizagem mais significativa principalmente para este público.

Esperava-se maior contextualização, principalmente nos conteúdos do terceiro ano, por se tratarem em grande parte de química orgânica, área da química que dá ênfase ao estudo das substâncias que constituem os seres vivos. Percebe-se que a transição do conhecimento, do momento em que ele é produzido até ser trabalhado em salas de aula, muitas vezes têm deixado 
para trás o contexto da descoberta, se distanciando da realidade e se tornando um conhecimento sistemático (Westphal, Pinheiro \& Teixeira, 2003).

Para contextualizar a química a nossa realidade de MT, as OC sugerem como tema conforto térmico, sexualidade, energia e agronegócio e seus impactos ambientais. Não foi trabalhado pelas unidades, na disciplina de química, o tema sobre sexualidade, conforto térmico também não foi registrado (Mato Grosso, 2010).

No quesito interdisciplinaridade, o destaque foi para temas interligados a física, algo esperado, já que estas disciplinas são tão próximas que inclusive já estiveram juntas em matrizes curriculares das escolas brasileiras, no início da nossa história. Outra temática que se destacou foram as relacionadas ao meio ambiente e ao contexto local. Esse tema é sugerido pelos documentos curriculares e foi bastante abordado no município, infelizmente não por todas as escolas, mas acredita-se que esse tema se faz necessário no cenário atual de consumismo desenfreado.

A baixa quantidade de conteúdos interdisciplinares relatados pode, em parte, ter relação com a dificuldade que os professores encontram em dialogar com os professores de outras disciplinas no momento do planejamento o que faz com os conteúdos sejam trabalhados em anos ou momentos diferentes (Herber, 2007).

No quadro 5, nota-se que a unidade $\mathrm{B}$ relatou muitas confraternizações e oficinas interdisciplinares, importantes para o seu contexto. Diante dessa conjuntura, é importante lembrar que conforme Saviani (2011) afirma, a escola não deve deixar de cumprir o essencial, o saber objetivo, e que essas atividades são secundárias e devem acontecer com o propósito de enriquecer as atividades curriculares.

A quarta categoria de análise foi sobre a História da Ciência e a Menção de Cientistas. A quinta e última categoria analisou os Conteúdos com características inovadoras contidos no currículo escolar de química nas escolas investigadas. Os quadros 8, 9 e 10 trazem os temas registrados sobre a História da Ciência e os Conteúdos com características inovadoras.

Quadro 8: História da ciência e conteúdos com características inovadoras nas turmas de primeiro ano

\begin{tabular}{|l|l|l|}
\hline & \multicolumn{1}{|c|}{ História da ciência/menção de cientistas } & Conteúdos com características inovadoras \\
\hline A & Nenhuma registrada. & Nenhuma registrada. \\
\hline
\end{tabular}




\begin{tabular}{|c|c|c|}
\hline A & Nenhuma registrada. & Nenhuma registrada. \\
\hline A2 & Breve panorama histórico da química. & Nenhuma registrada. \\
\hline A3 & Nenhuma registrada. & Nenhuma registrada. \\
\hline A4 & A descoberta do elétron e do próton. & Nenhuma registrada. \\
\hline A5 & Alquimia A teoria atômica de Dalton. & Nenhuma registrada. \\
\hline B & Nenhuma registrada. & $\begin{array}{l}\text { Ler e entender rótulos e embalagens. } \\
\text { Quantidades e proporções: do remédio ao } \\
\text { veneno. Fórum de diagnóstico da realidade } \\
\text { escolar. Bazar e gincana. }\end{array}$ \\
\hline $\mathrm{C}$ & Da alquimia a química. & Nenhuma registrada. \\
\hline $\mathrm{C} 1$ & A teoria sobre a origem do universo. & $\begin{array}{l}\text { Aula sobre a teoria de origem do universo } \\
\text { (como foi para EJA pareceu audacioso). }\end{array}$ \\
\hline $\mathrm{D}$ & A teoria atômica de Dalton. & $\begin{array}{l}\text { Aula de pesquisa com experimentos práticos. } \\
\text { Experimento prático: extintor caseiro a base } \\
\text { de } \mathrm{CO}_{2} \text {. }\end{array}$ \\
\hline D1 & $\begin{array}{l}\text { Os materiais de ontem e de hoje. Mudanças na obtenção e } \\
\text { no uso de recursos energéticos. Mudanças na obtenção e no } \\
\text { uso de recursos minerais. }\end{array}$ & Nenhuma registrada. \\
\hline D2 & $\begin{array}{l}\text { Catálogo dos anciões da comunidade com diversas práticas } \\
\text { e conhecimentos de medicamentos de origem vegetal e } \\
\text { animal usados na comunidade indígena local. }\end{array}$ & $\begin{array}{l}\text { Produção de medicamentos naturais a partir } \\
\text { do coco de piaçava para o consumo interno na } \\
\text { comunidade. Produção de livro com receitas } \\
\text { de medicamentos naturais. }\end{array}$ \\
\hline $\mathrm{E}$ & $\begin{array}{l}\text { Dalton e a teoria atômica. Modelo atômico de Thomsom, de } \\
\text { Rutherford, de Bohr e Enwin Schrodinger. Distribuição de } \\
\text { Linus Pauling. Lei de Mendeleiev. Lei de Moseley. }\end{array}$ & $\begin{array}{l}\text { Aula prática: teste de chamas. (não sei se pode } \\
\text { ser considerado inovador, porquê talvez eu } \\
\text { tivesse que considerar todos os experiementos } \\
\text { inovadores?) }\end{array}$ \\
\hline $\mathrm{F}$ & $\begin{array}{l}\text { A contribuição da química para a ciência. } \\
\text { Evolução histórica da classificação dos elementos: das } \\
\text { tríades a tabela periódica. A tabela de Mendeleiev. }\end{array}$ & Nenhuma registrada. \\
\hline $\mathrm{F} 1$ & $\begin{array}{l}\text { A contribuição da química para a ciência. } \\
\text { Evolução histórica da classificação dos elementos: das } \\
\text { tríades a tabela periódica. A tabela de Mendeleiev. }\end{array}$ & Nenhuma registrada. \\
\hline G & $\begin{array}{l}\text { Teorias ácido-base. Equação de Clapeyron. Lei de } \\
\text { Lavoisier. Lei de Proust. }\end{array}$ & Nenhuma registrada. \\
\hline G1 & Teorias ácido-base. & Nenhuma registrada. \\
\hline G2 & Da alquimia surge a química. Breve panorama histórico. & Nenhuma registrada. \\
\hline G3 & Nenhuma registrada. & Nenhuma registrada. \\
\hline G4 & $\begin{array}{l}\text { Alquimia versus Química: Ciência experimental. Leis } \\
\text { ponderais. Constante de Avogadro. }\end{array}$ & Nenhuma registrada. \\
\hline
\end{tabular}


G5 Modelos atômicos. Química e a evolução da sociedade. Nenhuma registrada.

História da química. Modelos atômicos de Dalton,

Thomson, Rutherford e Bohr.

H Nenhuma registrada.

Construção de uma balança improvisada com uso de objetos com massa conhecida para calibrar a balança. Experimento como atividade sobre transformações químicas.

Fonte: Dados coletados na pesquisa (2018-2020).

Quadro 9: História da ciência e conteúdos com características inovadoras nas turmas de segundo ano

\begin{tabular}{|c|c|c|}
\hline & História da ciência/menção à cientistas & Conteúdos com características inovadoras \\
\hline A & Ácido de Arrhenius e de Bronsted-Lowry & Nenhuma registrada. \\
\hline A1 & Nenhuma registrada. & Nenhuma registrada. \\
\hline A2 & Ácido de Arrhenius. & Nenhuma registrada. \\
\hline A3 & $\begin{array}{l}\text { O descarte dos materiais que utilizamos, como era e } \\
\text { como é. }\end{array}$ & Nenhuma registrada. \\
\hline A4 & Lei de Raoult. & Nenhuma registrada. \\
\hline A5 & Nenhuma registrada. & $\begin{array}{l}\text { Leitura sobre experiências feitas em laboratório e } \\
\text { noções práticas com materiais caseiros. }\end{array}$ \\
\hline $\mathrm{C}$ & Constante de Avogadro. Princípio de Le Chatelier. & Nenhuma registrada. \\
\hline $\mathrm{C} 1$ & A evolução dos modelos atômicos. & Nenhuma registrada. \\
\hline $\mathrm{D}$ & Nenhuma registrada. & $\begin{array}{l}\text { Aula de pesquisa com experimentos práticos. } \\
\text { Produção de maquete que representa estrutura } \\
\text { geológica, relevos e solos com experimentos da } \\
\text { despoluição da água. }\end{array}$ \\
\hline D1 & $\begin{array}{l}\text { Os materiais de ontem e de hoje. Mudanças na } \\
\text { obtenção e no uso de recursos energéticos. Mudanças } \\
\text { na obtenção e no uso de recursos minerais. }\end{array}$ & Nenhuma registrada. \\
\hline $\mathrm{E}$ & Nenhuma registrada. & $\begin{array}{l}\text { Documentário sobre } 100 \text { elementos indispensáveis. } \\
\text { (Não sei se é inovador) }\end{array}$ \\
\hline $\mathrm{F}$ & Lei de Hess. & Nenhuma registrada. \\
\hline F1 & Nenhuma registrada. & Nenhuma registrada. \\
\hline G & $\begin{array}{l}\text { Lei de Hess. Princípio de Le Chatelier. Pilha de } \\
\text { Daniel. }\end{array}$ & Nenhuma registrada. \\
\hline G1 & $\begin{array}{l}\text { Lei de Hess. Princípio de Le Chatelier. Pilha de } \\
\text { Daniel. }\end{array}$ & Nenhuma registrada. \\
\hline
\end{tabular}




\begin{tabular}{|c|c|c|}
\hline $\mathrm{G} 2$ & Lei de Hess. Princípio de Le Chatelier. & Nenhuma registrada. \\
\hline G3 & Princípio de Le Chatelier. Lei de Hess. & Nenhuma registrada. \\
\hline G4 & $\begin{array}{l}\text { Estrutura da matéria, o átomo: Dos gregos a Dalton. } \\
\text { Modelos atômicos: De Dalton a Rutherford/Bohr. } \\
\text { Histórico da tabela periódica: A tabela periódica } \\
\text { atual; lógica de construção e uso. Lei de Hess }\end{array}$ & Nenhuma registrada. \\
\hline G5 & Nenhuma registrada. & Nenhuma registrada. \\
\hline $\mathrm{H}$ & Nenhuma registrada. & $\begin{array}{l}\text { Construção de uma balança improvisada com uso } \\
\text { de objetos com massa conhecida para calibrar a } \\
\text { balança. Experimento como atividade sobre } \\
\text { transformações químicas. }\end{array}$ \\
\hline
\end{tabular}

Fonte: Dados coletados na pesquisa (2018-2020).

Quadro 10: História da ciência e conteúdos com características inovadoras nas turmas do terceiro ano

\begin{tabular}{|r|l|l|}
\hline & História da ciência/menção à cientistas & $\begin{array}{l}\text { Conteúdos com } \\
\text { inovadoras }\end{array}$ \\
\hline A & Postuladosísticas \\
\hline A2 & Ácidos de Arrhenius. & Nenhuma registrada. \\
\hline A4 & História da química orgânica. & $\begin{array}{l}\text { Bibliografia e índice remissivo. (não } \\
\text { detalhou o que foi feito) }\end{array}$ \\
\cline { 2 - 3 } C & Nenhuma registrada. & Nenhuma registrada. \\
\hline D & Nenhuma registrada. & Nenhuma registrada. \\
\hline F & $\begin{array}{l}\text { Introdução a química orgânica: Teoria da força vital. O modelo de } \\
\text { Lewis para moléculas orgânicas. }\end{array}$ & Nenhuma registrada. \\
\hline F1 & $\begin{array}{l}\text { Introdução a química orgânica: Teoria da força vital. O modelo de } \\
\text { Lewis para moléculas orgânicas. }\end{array}$ & Nenhuma registrada. \\
\hline G & Força de Van Der Waals. & Nenhuma registrada. \\
\hline G2 & Força de Van der Walls. & $\begin{array}{l}\text { História da química orgânica. A descoberta da radioatividade enha registrada. } \\
\text { utilização dos raios-X. }\end{array}$ \\
\hline G4 & Nenhuma registrada. \\
\hline
\end{tabular}

Fonte: Dados coletados na pesquisa (2018-2020)

A história da química apareceu de forma relevante, no primeiro ano (quadro 8), quando muitos livros abordam o tema, reforçando mais uma vez a fala de Damasceno, Wartha \& Silva (2009), sobre os livros nortearem os conteúdos em sala de aula, entretanto, na maioria dos outros 
casos, pareceu se tratar apenas da menção corriqueira do nome do cientista para abordar alguma teoria ou lei.

Quando se estuda a história de como determinado conceito foi elaborado, se torna mais fácil entender o conteúdo e até mesmo humanizar a ciência, já que o estudante entende a raiz lógica do assunto e até mesmo tem mais possibilidade se achar capaz de elaborar teorias e conclusões sobre os fenômenos a sua volta (Oki \& Moradillo, 2008).

As tendências de ensino percebidas no ensino regular, no geral, mantiveram uma base tradicional, e quando houve uma flexibilização curricular, esta voltou-se para assuntos atuais e questões cotidianas principalmente em escolas do campo. Houve registros de algumas atividades investigativas e também experimentais, mas a maioria não foi detalhada o suficiente para que se fosse possível perceber a tendência pedagógica com clareza.

Em relação as metodologias, em muitos casos, não foram especificadas, sendo descritas apenas como atividades/exercícios, as vezes de fixação ou complementares. Houve relatos de correção dessas atividades, revisão de conteúdos. A maioria das unidades registrou o termo avaliação, a minoria descreveu como escritas. As turmas de EJA, em sua maioria, não citaram o termo avaliação. A unidade $\mathrm{H}$ se destacou na descrição das metodologias desenvolvidas.

A escola $\mathrm{G}$ e as suas unidades trabalharam muitos conteúdos, quando comparadas as outras e foi a escola que chegou mais perto de ministrar todos os conteúdos sugeridos pelas OC (Mato Grosso, 2010). Entretanto, em relação a contextualização, instruída também pelas OC, houve pouquíssimas.

As escolas indígenas, na maior parte dos casos, ministraram menos conteúdos que as demais. Os temas, no geral, eram abordados em mais aulas, de forma contextualizada, com muitas atividades. Mas não necessariamente houve maiores aprofundamentos técnicocientíficos e sim maior prática por meio de atividades.

Pareceu haver um paradoxo, as escolas que chegaram mais perto de ministrar todos os conteúdos, acabaram por distanciar das contextualizações e interdisciplinaridades, metodologias estas, insistentemente mencionadas nas OC (Mato Grosso, 2010). Geralmente quanto mais se contextualizou, menos conteúdos foram ministrados.

As OC não foram atendidas por completo em nenhuma unidade e comparando a quantidade de exigências curriculares com a carga horária das aulas, que na maioria dos casos é somente uma aula semanal, com poucas exceções com duas aulas semanais, é perfeitamente 
compreensível. Cabe lembrar que esse currículo comum, proposto pela Secretaria de Estado de Educação, seria o mínimo que os estudantes teriam que aprender naquela determinada etapa de escolarização.

Acredita-se que as OC se trata de um documento interessantíssimo para a educação de MT, a questão é que ela também não consegue resolver as desigualdades socioculturais e tem se mostrado distante da realidade das salas de aula).

\section{Considerações Finais}

Esse estudo permitiu constatar que dentro da mesma rede de ensino, do mesmo município, o ensino de química apresentou disparidades, tanto na quantidade de conteúdos ministrados, como no nível de aprofundamento. Os conteúdos mais trabalhados foram: substâncias, propriedades da matéria, ligações e reações químicas, misturas e compostos orgânicos. $\mathrm{O}$ meio ambiente foi bastante trabalhado também, de forma contextualizada.

Os conceitos físicos estiveram muito presentes de forma interdisciplinar. A história da alquimia foi a mais citada, as demais, foram menções de cientistas sem aprofundamento histórico. Notou-se que as escolas do campo e as indígenas trouxeram temas e até mesmo metodologias diferentes que foram relevantes para seu meio social. Os métodos avaliativos não foram tão bem detalhados, mas soaram tradicionais.

Um sistema de avaliação como o atual não contempla a diversidade nem de um município, quem dirá de um país. O interessante seria uma mudança no sistema de avaliação e ingresso as universidades ou a opção menos prejudicial realmente é padronizar a base curricular da educação básica. Como o MEC sugere, essas diferenças são mesmo um problema para a sociedade, no cenário atual. Entretanto, assim como Lopes (1999), acredita-se na inexistência de um currículo neutro e imparcial. Um currículo imposto sempre valorizará as tradições culturais dos grupos dominantes e nesse ponto fica claro a relação do conhecimento escolar com a legitimação da sociedade capitalista.

O uso de um currículo comum pode desconsiderar as especificidades culturais locais, então cabe um bom senso quanto a construção do planejamento anual por parte dos professores No entanto, nesse estudo percebeu-se que, mesmo sendo um único contexto regional, o currículo de química desenvolvido nas escolas deste município apresentou diferenças, com especificidades socioculturais, ou seja, vários conteúdos ministrados foram diferentes entre as unidades, inclusive na quantidade e profundidade. 
É necessário que se faça uma pesquisa mais aprofundada, comparando as notas de todas as unidades com a quantidade de conteúdos ministrados, para quê, pragmaticamente consiga identificar o que está em melhor funcionamento no cenário atual de ingresso a universidades, a quantidade ou qualidade dos conteúdos. Necessita-se da realização de cursos voltados para os professores da rede estadual, sobre o ensino de química contextualizado e sobre aulas experimentais.

\section{Referências}

Bardin, L. (2012). Análise de conteúdo. Edições 70. São Paulo.

Brasil. (1999). Ministério da Educação. Secretaria de Educação Média e Tecnológica. Parâmetros Curriculares Nacionais: Ensino Médio. Brasília: MEC.

Brasil. (2002). Ministério da Educação. Secretaria de Educação Média e Tecnológica. Parâmetros Curriculares Nacionais $(P C N+)$. Brasília: MEC.

Casteleins, V. L. (2011). Dificuldades e benefícios que o docente encontra ao realizar aulas práticas de química. In: Congresso Nacional De Educação - EDUCERE, 10. Curitiba. Anais eletrônicos. Disponível em: <https://educere.bruc.com.br/CD2011/pdf/6331_3949.pdf>. Acesso em: 19 de jun. 2020.

Chassot, A. (2000). Alfabetização Científica. Questões e Desafios para a educação. Coleção Educação Química. Ijuí: Editora UNIJUI.

Chassot, A. (1990). A educação no ensino de química. Ijuí: Livraria UNIJUÍ Editora.

Damasceno, H. C.; Wartha, E. J. \& Silva, A. F. A. (2009). Conteúdos e Programas de Química no Ensino Médio: $O$ que realmente se ensina nas escolas de Itabuna, região sul da Bahia. In: Anais do VII Enpec, 2009, Florianópolis. VII Encontro Nacional de Pesquisas em Educação em Ciências (VII Enpec).

Fachin, O. (2006). Fundamentos de metodologia. 5.ed. São Paulo: Saraiva.

Fazenda, I. C. A. (1998). Didática e Interdisciplinaridade. Campinas, São Paulo: Papirus.

Herber, J. (2007). Currículos de química: uma reflexão coletiva. Dissertação (Mestrado) PUCRS - Faculdade de Física, Programa de Pós-graduação em Educação em Ciências e Matemática Porto Alegre.

Libâneo, J. C. (1982). Tendências pedagógicas na prática escolar. Revista da ANDE, 6(1). Disponível em: <https://praxistecnologica.files.wordpress.com/2014/08/tendencias_pedagogicas_liban eo.pdf> Acesso em: 19 de jun de 2020.

Lopes, A. R. C. (1999). Conhecimento escolar: ciência e cotidiano. Rio de Janeiro: Editora da UERJ.

Lopes, A. C. (2002). Os parâmetros curriculares nacionais para o ensino médio e a submissão 
ao mundo produtivo: o caso do conceito de contextualização. Educação \& Sociedade, Campinas, 23(80), p. 396.

Maceno, N. G. et al. (2011). A matriz de referência do ENEM 2009 e o desafio de recriar o currículo de química na educação básica. Química Nova na Escola, 33(3), p. 154.

Martins, A. M. (2000). Diretrizes Curriculares Nacionais para o Ensino Médio: Avaliação de Documento. Cadernos de Pesquisa, São Paulo: Fundação Carlos Chagas; Campinas: Autores Associados, 109(1), p. 67-87, mar.

Mato Grosso. (2010). Orientações curriculares: área de Ciências da Natureza e Matemática: Educação Básica. SEDUC/MT. Cuiabá: Defanti.

Moehlecke, S. (2012). O ensino médio e as novas diretrizes curriculares nacionais: entre recorrências e novas inquietações. Revista Brasileira de Educação, 17(49), p. 39-58, jan./abr.

Mortimer, E. F. et al. (2000). A proposta curricular de química do Estado de Minas Gerais: fundamentos e pressupostos. Revista Química Nova, 23(2), p. 273-283.

Oki, M. C. M. \& Moradillo, E. F. (2008). O ensino de história da química: Contribuindo para a compreensão da natureza da ciência. Ciência \& Educação, 14(1), p. 69.

Prado, I. G. A. (2000). O MEC e a reorganização curricular. São Paulo em Perspectiva, 14(1), p. 94-97, jan/mar.

Saviani, D. (2011). Pedagogia histórico-crítica: primeiras aproximações. $11^{\text {th }}$ rev. Campinas: Autores Associados.

Silva, M. R. (2015). Currículo, ensino médio e BNCC Um cenário de disputas. Revista Retratos da Escola, Brasília, 9(17), p. 367-379, jul./dez.

Westphal, M.; Pinheiro, T. C. \& Teixeira, C. da S. (2003). PCN-EM: Contextualização ou Recontextualização. In: Anais do IV Enpec, 2003, Baurú/SP. IV Encontro Nacional de Pesquisas em Educação em Ciências (IV Enpec).

Autores:

Lunara Lanna Lima. Instituto Federal de Mato Grosso (IFMT) Campus Confresa; Brasil Especialização em Ensino de Ciências pelo IFMT Campus Confresa. Graduação em Licenciatura em Ciências da Natureza com Habilitação em Química pelo IFMT Campus Confresa. Professora de química na Educação Básica (SEDUC/MT).

Marcelo Franco Leão. marcelo.leao@cfs.ifmt.edu.br. http://orcid.org/0000-0002-9184-916X Instituto Federal de Mato Grosso (IFMT) Campus Confresa; Brasil Doutorado em Educação em Ciências (UFRGS). Mestre em Ensino (UNIVATES). Especialização em Orientação Educacional (Dom Alberto) e em Relações Raciais na Educação e na Sociedade Brasileira (UFMT). Graduação em Licenciatura em Química (UNISC) e em Física (UNEMAT). Professor do Departamento de Ensino do IFMT Campus Confresa. Membro do Grupo de Pesquisa Ensino de Ciências e Matemática no Baixo Araguaia

(EnCiMa). 